\title{
Jumps in Oil Prices: The Role of Economic News
}

\author{
John Elder*, Hong Miao** and Sanjay Ramchander***
}

May 2012

Revised: December 2012

Previous research has been unable to identify a strong link between oil prices and economic news. We reexamine this relationship using high frequency intraday data and relatively new methodology that we use to estimate jumps in oil prices. We find a surprisingly strong relation between high frequency jumps in oil prices and the arrival of new economic information, with the largest jumps in oil prices tending to be preceded identifiable economic news. These results indicate that oil prices respond very rapidly to new economic data in ways that appear consistent with economic theory, and they suggest that economic news, rather than speculation unrelated to the economic environment, drives jumps in oil prices.

Key Words: oil, jumps, macroeconomic news announcements

JEL Classification: G14, G17, C22

\footnotetext{
* Corresponding author. Professor, Department of Finance and Real Estate, Colorado State University. Email: John.Elder@business.colostate.edu.

** Assistant Professor, Department of Finance and Real Estate, Colorado State University. Email: Hong.Miao@business.colostate.edu.

*** Professor, Department of Finance and Real Estate, Colorado State University. Email: Sanjay.Ramchander@business.colostate.edu.

We thank Mohamed Ariff , Lutz Kilian, Leo Krippner, Matteo Manera, two anonymous referees and seminar participants at the 2012 Australasian Finance and Banking Conference for helpful comments on an earlier draft of this paper.
} 


\section{INTRODUCTION}

There has recently been considerable interest in whether oil prices reflect economic fundamentals or whether they are distorted by excessive speculative forces that may be unrelated to the economic environment. This interest has been driven by volatility in oil prices coupled with increased trading in oil futures by both professional investors and retail investors via investment vehicles such as exchanged traded funds, which disproportionally take long positions in oil futures.

Empirical investigations on the role of speculation have taken several different approaches. ${ }^{1}$ One approach examines the relation between spot prices of oil, futures prices, and, in some cases, inventories and volume, See, for example, Tang and Xiong (2011), Hamilton and Wu (2012a and 2012b), Kilian and Murphy (2012) and Fattouh, Kilian and Mahadeva (2012), as well as the policy debate entailed in Masters (2008). Another approach examines whether economic fundamentals can explain trends in oil prices. For example, Hamilton (2009) and Kilian and Hicks (2012) examine whether the rapid increase in oil prices during prior to 2009 can be explained by unexpected growth in demand.

A third approach involves the relation between oil prices and economic fundamentals at higher frequencies. Kilian and Vega (2011) conduct such an investigation and find little evidence that oil prices respond to macroeconomic news releases at daily and monthly horizons. Chatrath, Miao and Ramchander (2011), recognizing the stock-flow distinction in commodities, use intraday data to investigate whether oil prices are linked to macroeconomic events. Similar to Kilian and Vega, they do not find strong evidence of a systematic response of oil prices to economic news.

\footnotetext{
${ }^{1}$ The notion of speculation in oil markets is more nuanced than discussed here. For an excellent overview, see Fattouh, Kilian and Mahadeva (2012).
} 
In this paper, we reinvestigate the relation between oil prices and economic fundamentals using a different methodology with very high frequency, intraday data on oil prices (five-minute intervals). The methodology we employ identifies relatively large movements in the conditional mean of (log) oil prices over arbitrarily short intervals. These movements are known as "jumps," and we investigate whether these jumps in oil prices tend to coincide with the arrival of new economic information.

The theoretical foundation for identifying jumps in asset prices is developed in several recent papers, including Lee and Mykland (2008) and Barndorff-Nielsen and Shephard $(2004,2006)$. These authors develop a relatively simple test statistic for jumps in the log price process, along with a measure of sampling variability that allows for hypothesis tests. The jump methodology has been recently utilized in several recent studies, including Maheu and McCurdy (2004), Rangel. (2011), Evans (2011), Lahaye, Laurent and Neely (2011) and Lee (2012).

Our approach is more focused than previous studies that investigate the relation between oil prices and economic news, in that we analyze only these discontinuities in oil prices. We think this approach is reasonable, in part due to the challenges encountered by previous studies, and in part because it effectively compensates for features of the data, such as the unobservable nature of the "surprise" component of a news announcement that makes it difficult to link noisily measured economic surprises with directional changes in oil prices.

Our results indicate a surprisingly strong link between jumps in oil prices and economic announcements. In particular, we find that there are a disproportionately large number of jumps in oil prices at four intervals during the day, three of which correspond to regular economic announcements and one of which corresponds to the market opening. These intervals are approximately 8:30 am and 10:30 am, which correspond to domestic news releases, 5:00 am, 
which corresponds to the release of economic news in Europe, and 9:00 am, which corresponds to the opening of trading in the pits.

We examine the largest jumps in oil prices and find that eighteen of the twenty largest jumps at 8:35 am are preceded by a scheduled economic announcement, with stronger than expected economic news tending to precede positive oil jumps, and weaker than expected economic news tending to precede negative jumps. Similarly, eighteen of the twenty largest jumps at 10:35 am are preceded by a scheduled announcement on crude oil inventories, with higher than expected inventories tending to precede negative jumps, and lower than expected inventories tending to be preceded by positive jumps.

The interval around 8:35 am is perhaps the most relevant for U.S. macroeconomic announcements, and we find that more than $70 \%$ of the jumps in oil prices at this interval are preceded by a relatively few number of economic news releases. As with other studies on macroeconomic announcements, the employment situation report plays a key role, with more than $30 \%$ of the announcements on the change in nonfarm payrolls followed by jumps in oil prices.

Overall, our results suggest that jumps in oil prices are closely tied to new economic information that is pertinent to the global market for oil. Given the very high frequency of our data (five-minute intervals), the evidence that oil prices are inextricably linked to substantive new economic information appears overwhelming. In terms of the debate related to the effects of speculation in oil markets, our analysis offers one contribution to a complicated puzzle. That is, oil prices react very quickly and rationally to pertinent economic information, and such responses dominate the variation in oil prices due to speculative forces that are unrelated to economic fundamentals. 
The remainder of the paper is organized as follows: section 2 describes the procedure for estimating jumps; section 3 describes the data and section 4 presents the results. Section 5 concludes.

\section{JUMP ESTIMATION}

We use the modified jump test proposed by Lee and Mykland (2008) to identify intraday jumps. ${ }^{2}$ This test statistic has the null of no jumps over $K$ observations between $t_{i-1}$ and $t_{i}$ on day $t$, and is simply

$\mathcal{L}(i)=\frac{r_{t_{i}}}{\widehat{\sigma_{t_{l}}}}$

where, $\widehat{\sigma_{t_{l}}}$ denotes the realized bipower variation, which is the product of adjacent returns

${\widehat{\sigma_{t_{l}}}}^{2}=\frac{1}{K-2} \sum_{j=i-K+3}^{i-1}\left|r_{t_{j}}\right|\left|r_{t_{j-1}}\right|$.

The selection of the window size $K$ is determined by the sampling frequency. Lee and Mykland suggest that the optimal choice for $K$ is the smallest integer such that $K \geq \sqrt{252 \times \text { nobs }}$, where nobs is the number of observations per day. The optimal window sizes for one-minute, five-minute, 10-minute, 15-minute, and 30-minute frequency data are therefore 603, 270, 191, 156, and 110, respectively.

To conduct inference, some knowledge of the distribution of the test statistic (2) is required. We use the rejection region derived by Lee and Mykland (2008), which they show to have desirable properties asymptotically, for inference. More details on the calculation of the rejection region is described in the appendix.

The motivation for the test statistic described by equation (2) is both relevant and straightforward. The operational assumption is that the underlying

\footnotetext{
${ }^{2}$ Andersen et al. (2010) propose an alternative procedure to identify jumps. We also generate results using this procedure and find results similar to those reported here.
} 
logarithmic asset price $p_{t}$ can be expressed as a continuous time jump diffusion process

$$
d p_{t}=\mu_{t} d t+\sigma_{t} d w_{t}+\kappa_{t} d q_{t}, \quad t \geq 0,
$$

where, $\mu_{t}$ and $\sigma_{t}$ are the drift and instantaneous volatility, $w_{t}$ is standard Brownian motion independent of the drift, and $q_{t}$ is a normalized counting process such that $d q_{t}=1$ indicates a jump at time $t$, and $d q_{t}=0$ otherwise, with the $\kappa_{t}$ process describing the size of the corresponding discrete jump in the logarithmic price process. Note that the jump process in equation (3) describes the evolution of the conditional mean of $p_{t}$.

Barndorff-Nielsen and Shephard (2002) provide an intuitive basis for detecting jumps based on realized variation (RV) and realized bipower variation (BV). $\mathrm{RV}$ is defined as the sum of intraday squared returns

$$
R V_{t}=\sum_{j=1}^{M} r_{t_{j}}^{2}, \quad t=1, \ldots, T
$$

where $r_{t_{j}}$ is the $j^{\text {th }}$ intraday return on day $t$. From the theory of quadratic variation, $R V_{t}$ is a consistent estimator of the daily increment to the quadratic variation for the underlying log-price process in equation (3) (see Andersen, Bollerslev and Diebold, 2002). That is, as $M \rightarrow \infty$,

$$
R V_{t} \rightarrow p \int_{t-1}^{t} \sigma_{s}^{2} d s+\sum_{s=q_{t-1}}^{q_{t}} \kappa_{s}^{2}, \quad t=1, \ldots, T
$$

Where $\rightarrow{ }_{p}$ denotes convergence in probability. The first term in equation (5) represents the instantaneous volatility and the second term $\left(\sum_{s=q_{t-1}}^{q_{t}} \kappa_{s}^{2}\right)$ represents variation attributed to jumps.

BV is defined as the scaled sum of the product of adjacent highfrequency returns:

$$
B V_{t} \equiv \mu_{1}^{-2} \sum_{j=2}^{M}\left|r_{t_{j}}\right|\left|r_{t_{j-1}}\right|, \quad t=1, \ldots, T
$$

where $\mu_{1}=\sqrt{2 / \pi}$ is the mean of the absolute value of the standard normal random variate. Barndorff-Nielsen and Shephard (2004, 2006) show BV converges in probability to instantaneous volatility, 


$$
B V_{t} \rightarrow_{p} \int_{t-1}^{t} \sigma_{s}^{2} d s, \quad t=1, \ldots, T
$$

The contribution of jumps to RV is identified by disentangling the continuous and discontinuous components of quadratic variation. Specifically, from equation (5), the difference between $R V_{\mathrm{t}}$ and $B V_{\mathrm{t}}$ therefore provides a consistent estimate of the contribution of the jump component to the RV

$$
R V_{t}-B V_{t} \rightarrow \sum_{s=q_{t-1}}^{q_{t}} \kappa_{s}^{2}, \quad t=1, \ldots, T
$$

Note that this describes a test for the occurrence of a jump over the course of a trading day. Our analysis examines the relation between jumps and the intraday time of the news release, so we use the modified jump test proposed by Lee and Mykland (2008) to identify intraday jumps given by equations (1) and (2).

\section{DATA DESCRIPTION}

The oil price data we use are intraday observations of futures prices of WTI crude oil over the period January 2005 to December 2010. The futures are traded on the CME (NYMEX) through both open outcry auction and the Globex electronic trading platform. Trading in the CME pit occurs on weekdays between 9:00 am - 2:30 pm U.S. Eastern Time, and electronic trading begins at 6:00 pm and runs through 5:15 pm the next day on Sunday through Friday. Electronic trading breaks for only 45-minutes each day starting at 5:15 pm. The contract unit is for 1,000 barrels and the price is quoted in U.S. dollars.

We form a continuous time series of prices by combining contracts with the greatest number of transactions. In particular, we roll the front-month contract into the first back-month contract when the daily transactions of the current front-month contract are exceeded by the first back-month contract. This procedure avoids stale prices associated with thinly traded contracts.

We consider several different scheduled macroeconomic

announcements that are released at 8:30 am as well as the Department of 
Energy's (DOE) total change in crude oil, which is released at 10:30 am. ${ }^{3}$ For each type of announcement we obtain a time series of the actual values as well as market forecasts based on survey expectations. This data is obtained from Bloomberg. In order to compare the relative magnitude of each economic announcement, the realized announcement surprise is standardized by dividing the difference between the realized value and the consensus forecast by its sample time-series standard deviation. That is,

$S_{i, t}=\frac{A_{i, t}-E_{i, t}}{\sigma_{i}}$

where $S_{i, t}$ is the surprise element of the announcement of type $i$ at time $t, A_{i, t}$ is the actual value of the announcement, $E_{i, t}$ is the corresponding consensus forecast, and $\sigma_{i}$ is the sample standard deviation of $\left(A_{i, t}-E_{i, t}\right)$.

Descriptive statistics for the nine pre-scheduled announcements at 8:30 am and the single pre-scheduled news announcement at 10:30 am are reported in Table 1. Of the 8:30 am announcements, the broadest based measures of economic activity are advanced retail sales, the change in nonfarm payrolls and gross domestic product.

The announcement that we have labeled the "change in nonfarm payrolls” is actually part of the more comprehensive employment situation report on the domestic labor market, which includes data on the unemployment, labor force, the duration of unemployment as well as data from both the household and establishment surveys. The other broad based measures of economic activity are advanced retail sales and GDP. They include information that overlaps considerably with other announcements. For example, the final GDP report is released quarterly, but personal income and spending, which

\footnotetext{
${ }^{3}$ We do not describe the macroeconomic data in detail here, since it is described in detail elsewhere, such as Ederington and Lee (1993), Simpson and Ramchander (2004) and Elder, Miao and Ramchander (2011).
} 
account for nearly three-quarters of GDP, are released monthly. Similarly, personal income and spending tend to be correlated with advanced retail sales.

The employment situation report is therefore unique in the sense that it is a broad measure of economic activity that is released monthly, and there are few other reports that contain such comprehensive information on the domestic labor market. Ex ante, we would therefore expect this report to have a relatively high level of independent information content on the state of the economy.

The 8:30 am announcements are released 30 minutes before the opening of the CME trading pit, so we obtain oil prices from the Globex electronic market. Over our sample, there are 72 monthly news announcements for each of the 9 economic variables released at 8:30 am. The data for the change in crude oil inventory is released weekly at 10:30 am which is ninety minutes after the opening of the CME futures pit market, and thus their price impact is investigated by using the pit/Globex prices - when the pit and Globex markets are both open. During the sample period there are 312 announcements on crude oil inventories.

\section{EMPIRICAL RESULTS}

\section{Jumps in Oil Prices}

In this section we apply Lee and Myklands’ (2008) jump identification procedure to crude oil futures prices. We first need to determine the frequency at which to calculate returns. At higher frequencies the null hypothesis of no jumps tends to be rejected more often, indicating the possibility of an increase in the probability of a Type I error. Dumitru and Urga (2012) suggest an appropriate frequency is one for which the proportion of jumps is relatively stable around neighboring frequencies. As reported later in this section, we find that returns calculated at five-minute intervals satisfy this criterion. 
A second issue is the appropriate level of significance for the jump identification test. Dumitru and Urga (2012) and others suggest utilizing a relatively high level of significance, so we reports results at the $1 \%$ level, which is comparable to Bjursell, Wang and Webb (2010) and Dumitru and Urga (2012). Evans (2011) uses $0.1 \%$ and Lee and Mykland (2008) use 5\%. To be conservative, we report results for jumps at the $1 \%$ level, but we also ensure that we obtain comparable results at the $0.1 \%$ significance level.

To gauge the appropriate frequency, we initially apply Lee and Myklands' (2008) jump identification test to our sample of data at frequencies of 1-minute, 5-minutes, 10-minutes, 15-minutes, and 30-minutes, using observations from both pit trading and Globex. We estimate the number of jumps at the $0.1 \%, 1 \%$, and $5 \%$ significance levels, and report the results in Table 2. The results indicate that the probability of observing a jump in the Globex series at the highest frequency (1-minute) is substantially greater than at other frequencies. In particular, decreasing the sample frequency from 1-minute to 5 -minutes results in a more than $60 \%$ decrease in detected jumps in Globex price series at all three levels of significance. In contrast, the corresponding jump proportion from the trading pit is relatively stable. For instance, at the $1 \%$ significance level, the proportion of jumps in the pit prices ranges from $0.43 \%$ and $0.51 \%$. Interestingly, the proportion of jumps is the lowest at the 1 -minute frequency. Beyond the 1-minute intervals, the proportion of jumps in the both price series is relatively stable. This suggests that a sample frequency of fiveminutes is reasonable for our analysis.

Table 3 presents summary statistics for five-minute returns for crude oil futures from both pit and Globex return series. At the five-minute interval, the pit return series has about 95,000 return observations, while Globex has about 285,000 . For both return series, the mean return is close to zero, with relatively small skewness and high kurtosis. More specifically, the standard deviation of 
pit returns is about $140 \%$ higher than the standard deviation of Globex returns. These differences in the return series, likely partly due to the lower liquidity during many of the Globex trading hours, suggest that we should investigate their relation to economic news announcements separately, rather than combining them together into one continuous series.

Table 3 also reports descriptive statistics on the jumps in the fiveminute return series identified at the $1 \%$ level of significance. We define the trading day as 9:00 am to 2:30 pm for the pit and from 2:30 pm to 9:00 am the next day for Globex. Several features are relevant to note. First, about 68.13\% total number of trading days contain jumps in the Globex series, and about 21.55\% in the pit, with the average number of jumps on these days about 2.01 (Globex) and 1.31 (pit). Second, the total number of jumps is 2,026 on Globex versus 417 for the pit. The larger number of jumps on Globex may be due to more idiosyncratic shock during after-hours trading. Finally, the magnitudes of the jumps are large relative to the average absolute return of all observations - about six to seven times larger. Third, the average jump size in the pit price series is nearly 1.5 times larger than for the Globex series (1.07\% vs. $0.44 \%)$. These differences lend further support to our earlier observation that we should investigate the properties of jumps in these two series separately, as the greater volatility of the pit return series may lead to under-identification of jumps in the Globex return series.

Finally, the jump statistics in Table 3 illustrate the asymmetry of jumps, as the number of negative jumps exceeds the number of positive jumps, and the negative jumps tend to be larger in magnitude. For example, of the 417 jumps in the pit price series, 250 (60\%) are negative.

\section{Jumps and Economic Announcements}


Recent studies find that a nontrivial proportion of jumps in exchange rates (Lahaye et al., 2010) and stock returns (Evans, 2011) can be related to U.S. macroeconomic news announcements. The relation between U.S. macroeconomic announcements and oil prices, however, has thus far been difficult to identify. For example, Kilian and Vega (2011) do not find strong evidence of a relation between daily oil returns and macroeconomic announcements, and Chatrath, Miao and Ramchander (2011) find only weak evidence of a link using intraday data. The jump identification methodology provides another method for potentially establishing this link, by identifying the largest price movements.

A histogram of jumps by time of day at five-minute intervals is plotted in Figure 1. The jumps tend to cluster during a few intervals, with more than 70 jumps at 5:05 am, 8:35 am, 9:00 am, and 10:35 am intervals. The next highest cluster is about 40 jumps at 6:00 pm.

The 9:00 am interval corresponds to the start of pit trading, and the other three time intervals with more than 70 jumps correspond to times of major macroeconomic news releases. At 5:00 am, several major macroeconomic announcements for the European Union are announced, including the Euro-zone consumer price index, producer price index and unemployment rate. At 8:30 am, several major U.S. macroeconomic news announcements for the U.S. are scheduled, as detailed in Table 1. Similarly, at 10:30 am, data on oil inventories, i.e., the weekly total change in US crude oil inventories, is released by the U.S. Department of Energy. This figure alone therefore provides considerable evidence that intraday jumps in oil prices are driven by economic fundamentals, rather than speculative components unrelated to economic fundamentals.

To further investigate whether the 8:35 am and 10:35 am jumps may be related to domestic news announcements, we sort the identified jumps by magnitude (absolute value) and examine whether an economic news 
announcement occurred within the previous five-minute interval. The top twenty jumps during the 8:35 am and 10:35 intervals are listed in Table 4. During the 8:35 am interval, 18 of the largest 20 jumps are preceded by at least one macroeconomic announcement. The sixth, seventh and fourteenth jumps are preceded by two macroeconomic announcements. Of these 18 macro announcements, 11 occur after the Bureau of Labor Statistics' release on the change in nonfarm payrolls, three occur after the news release on advanced retail sales, and two occur after the producer price index.

The relationship between the signs of 8:35 jumps and the sign of macroeconomic news surprises is, in the vast majority of instances, positive. For example, the largest surprise, a 1.8741\% jump on August 7, 2009, follows a 1.171 standard deviation surprise in nonfarm payrolls. The second largest surprise, a -1.5321\% jump on December 5, 2008, follows a -2.9725 standard deviation surprise in the changes in nonfarm payrolls. That is, it appears as though a better than expected change in payrolls may be interpreted as economic growth being greater than expected, which may tend to increase the demand for, and therefore the price of, oil.

The 10:35 am jumps show a similar relation to news announcements, with 18 of the top 20 occurring after the weekly release of crude oil inventories. The signs between the jumps and the surprise component of the inventory announcement are opposite in 16 out of 18 cases, indicating that oil returns tend to be negative when inventories are higher than expected. This is, of course, indicative of a downward sloping demand for oil. More specifically, there are eight unexpected increases in oil inventories followed by negative jumps in oil prices and eight unexpected decreases in inventories followed by positive jumps.

The results described in Table 4 certainly suggest that large moves in oil prices are related to substantive economic events pertinent to the global market for oil rather than random speculative forces. These results, however, are 
based only on the most extreme jumps in oil prices. To investigate whether macroeconomic events may be related to smaller jumps in oil prices, we match all the 8:35 am and 10:35 am jumps with the news releases described in Table 1.

These results are reported in Table 5, with the columns labeled "Matched" and "Percentage" referring to the number and proportion of each economic announcement that can be linked to a jump in oil prices. For example, during our sample, 23 of the 72 releases (31.94\%) on the changes in nonfarm payrolls are linked to jumps in oil prices at 8:35 am. As described previously, we should not be surprised that the information content in the nonfarm payrolls is relatively high, given the unique information content of this report. This has been recognized previously by several researchers including Andersen and Bollerslev (1998) who refer to the employment situation report as the "king" of all announcements. Two other news announcements, GDP and personal consumption have more than $10 \%$ of the announcements associated with jumps. Overall, for the 78 jumps in oil prices at 8:35 am, 56 (71.79\%) are preceded by one of the news announcements listed in Table 1.

The relationship between oil prices and the oil inventory announcements is even more dramatic, with 64 out of 75 jumps (85.3\%) in this time interval preceded by crude oil inventory announcements. Viewed from another perspective, 64 of the total 312 (20.5\%) weekly announcements on crude oil inventories are followed by 10:35 am jumps.

The results thus far suggest that jumps in oil prices tend to be associated with substantive economic news, and that a relatively small number of economic announcements precede a substantial proportion of jumps in oil prices. In the next section, we investigate this relationship further.

\section{The Marginal Effect of Economic News Announcements}


The results from the previous section suggest that jumps in oil prices are not randomly distributed throughout the trading day as they might be in a purely speculative environment. Rather, our results thus far indicate that substantive new economic information tends to precede significant jumps in oil prices. This analysis therefore highlights the role of news announcements with substantive economic content.

A separate question is whether we can identify a more systematic relation between economic news and the sign and magnitude of jumps in oil prices. To investigate such a relation we regress jumps that are preceded by economic news announcements on the standardized surprise of the announcements. To allow for positive and negative surprises to have asymmetric effects, we include them as separate covariates in the regression. In particular, we estimate a regression of the following form

$$
j p_{t_{j+1}}=c+\sum_{i=1}^{n} c_{i}^{+} S A_{i, t_{j}}^{+}+\sum_{i=1}^{n} c_{i}^{-} S A_{i, t_{j}}^{-}+\varepsilon_{t_{j+1}},
$$

where $j p_{t_{j+1}}$ refers to the $8: 35$ am or $10: 35$ am jump return and $S A_{i, t_{j}}^{+}$, and $S A_{i, t_{j}}^{-}$are the positive and negative standardized surprises of the $i^{\text {th }}$ news announcement. The results are reported in Table 6, sorted by positive and negative news surprises.

The first three columns report the regression results for the 8:35 am jumps. Two comments are noteworthy. This first is that the change in non-farm payrolls is significant, with p-values less than 0.05. Positive surprises in the change in nonfarm payrolls are associated with positive jumps in oil prices, and the relevant coefficient is highly significant. In particular, a realization of nonfarm payrolls that is one standard deviation greater than expected results in $0.64 \%$ jump in oil returns. This jump in oil returns may appear small (\$0.60 if the price of crude oil is $\$ 100$ per barrel), but it is measured over a very short interval, and it is six times the standard deviation of five-minute oil returns on the Globex market (which, from Table 1, is only $0.10 \%$ ). Similarly, unexpected 
declines in nonfarm payrolls tend to be followed by negative jumps (the coefficient is positive, but is multiplied by the negative realization of the news announcement), with a one standard deviation surprise decline in nonfarm payrolls followed by a $-0.3333 \%$ jump in oil prices.

The other noteworthy comments from Table 6 are that none of the other coefficients on news announcements are statistically significant. This highlights the difficulty often encountered in attempting to empirically identify systematic links between economic announcements and crude oil returns (see, for example, Chatrath, Miao and Ramchander, 2012). Given our earlier evidence that large surprises tend to be associated with jumps in oil prices, these results suggest that the difficultly may stem from attempting to relate small economic surprises to oil prices, perhaps because we have not measured the anticipated component of the economic "surprise" very accurately.

The second three columns of Table 6 report comparable regression results for the 10:30 am announcement on crude oil inventories. The link between inventories and oil price jumps is estimated more precisely, as the coefficient on both positive and negative standardized inventory surprises are highly significant. The response of oil to a one-standard deviation surprise is of a similar magnitude to the change in nonfarm payrolls, with coefficients of 0.7808 and -0.5275 . Again, this sign is as we would expect, with higher inventories resulting in lower oil prices, and lower inventories (negative surprises) resulting in higher prices (with a negative surprise multiplied by a negative coefficient). The relatively high adjusted R-squared for second model in Table 6 indicates that crude oil inventories explain a substantial fraction of the variation in oil return jumps during this interval.

These findings should be interpreted with some caution since we cannot say whether changes in inventory levels themselves are a result of speculative forces. 


\section{Are News Related Jumps Different?}

Our analysis thus far establishes a strong link between macroeconomic news and jumps in oil futures prices. However, while jumps that follow news announcements account for a large portion of large jumps, they account for only a small proportion of the total number of jumps. It is therefore natural to investigate whether jumps related to news announcements are different from non-news related jumps. To address this issue, we compare the absolute value of jumps, the jump component of the total variance, and the contribution of jumps to daily realized volatility. As discussed in the methodology section, the difference between the realized variance and the bi-power variation should converge to the jump component of the instantaneous volatility. The jump component of the instantaneous volatility is just the difference between realized volatility and bi-power variation. For days with multiple intraday jumps, we compute the contribution of each jump by taking the difference between the realized variance and the bi-power variance and subtracting the squared returns of the other jumps during the same day.

These results are reported in Table 7. The mean absolute value of the news related jumps on Globex at 8:35 am is $0.65 \%$ which is about $50 \%$ higher than the mean absolute value of the non-news related jumps (0.43\%). In addition, the average jump variance for news related jumps is $0.24 \%$, which is substantially higher than the average jump variance for non-news related jumps (0.16\%). The average contribution of jumps to daily realized volatility (JV/RV), however, is very similar for both news and non-news days (9.27\% vs. $8.57 \%)$. In summary, news related jumps from Globex are larger and more volatile than non-news related jumps, but their contribution to total variance is quite similar.

The pit session is used to identify jumps at 10:35 am. For these announcements, we find that the absolute sizes of news and non-news related jumps are similar $(1.11 \%$ vs. $1.06 \%)$, as are the jump variances $(0.81 \%$ and 
$0.74 \%$ ). The contribution of news related jumps to the daily realized volatility is, however, substantially larger than non-news related jumps (17.90\% vs. $11.12 \%)$. This confirms the strong information content conveyed by unexpected changes in crude oil inventories, and may have relevance to the literature relating oil price volatility to economic growth (cf. Bredin, Elder and Fountas, 2011).

To further examine the differences between news related and non-news related jumps, we investigate the volatility persistence of jumps. Following Ederington and Lee (1993) and Evans (2011), we run the following regression on the subsample that includes only intraday jumps:

$r_{t_{j+i}}^{2}=\beta_{n j} N J D_{t_{j}}+\beta_{n n j} N N J D_{t_{j}}+\varepsilon_{t_{j+i}}$, for $i=1$ to 5 .

where, $r_{t_{j+i}}$ represents the five-minute return in intraday interval $j+i$, if a jump is obtained in the intraday interval $j+1 . N J D_{t_{j}}$ and $N N J D_{t_{j}}$ are dummy variables equal to one if the intraday jump is news related and non-news related, respectively. For example, if there is a news release at 8:30 am and a jump at 8:35 am on day $t$, the five-minute returns at 8:35 am, 8:40 am, ..., and 9:00 am are regressed against $N J D_{t_{j}}=1$, and $N N J D_{t_{j}}=0$, respectively. Similarly, if there is a jump at 10:00 am (considered a non-news related jump), then the returns at 10:00 am, 10:05 am, .., 10:25 am are regressed against $N J D_{t_{j}}=$ 0 , and $N N J D_{t_{j}}=1$.

These results are reported in Table 8. They suggest that there is only weak evidence of volatility persistence after jumps. Examining the results for Globex session (Panel A) we find that regressing all the 8:35 am jumps to a news related dummy results in a positive coefficient of 0.55 which is about two times the coefficient value for non-news jumps. The coefficients for the subsequent five minute interval returns are very close for news related and nonnews related jumps (0.0732 vs. 0.0693). The coefficients on all six subsequent intervals are highly significant, and decline toward zero, so that the statistical 
significance is high while the economic significance after several intervals may be moderate. The results from the pit session (Panel B) show a similar pattern of volatility persistence. Overall, the results from Table 8 suggest that the price shocks due to economic news have some persistence, but that it dissipates relatively quickly.

\section{CONCLUSION}

The factors driving oil prices have been the subject of considerable debate and scrutiny, with interest in the role of speculative forces relative to economic fundamentals. Contributing to this debate has been the inability to identify a strong link between oil prices and economic news. In this paper, we reexamine this relationship using high frequency intraday data and relatively new methodology that we use to estimate jumps in oil prices. Our results show a surprisingly strong correspondence between high frequency jumps in oil prices and the arrival of new economic information, with the vast majority of large jumps preceded by either macroeconomic announcements or announcements related to crude oil inventories. As with other studies on macro announcements, the employment situation report plays a key role, with more than $30 \%$ of the announcements on the change in nonfarm payrolls preceding jumps in oil prices.

Overall, our results suggest that jumps in oil prices are closely tied to new economic information that is pertinent to the global market for oil. Given the very high frequency of our data (five-minute intervals), the evidence that oil prices respond very quickly to substantive new economic information appears overwhelming. Our results therefore provide one contribution to a complicated debate on the role of speculation in oil markets. That is, jumps in oil prices, particularly large jumps, tend not to be driven by speculative forces unrelated to the economic environment, but are driven by rational responses to pertinent economic information. 


\section{References}

Adams, G., G. McQueen and R. Wood (2004). “The Effects of Inflation News on High Frequency Stock Returns.” Journal of Business 77: 547-574.

Andersen, T.G., and T. Bollerslev (1998). "Deutsche Mark-Dollar Volatility: Intraday Activity Patterns, Macroeconomic Announcements, and Longer Run Dependencies.” Journal of Finance 53: 219-265.

Andersen, T.G., T. Bollerslev, F.X. Diebold and H. Ebens (2001). “The Distribution of Realized Stock Return Volatility.” Journal of Financial Economics 61: 43-76.

Andersen, T.G., T. Bollerslev and D. Dobrev (2007). "No-arbitrage Semimartingale Restrictions for Continuous-time Volatility Models Subject to Leverage Effects, Jumps and i.i.d. Noise: Theory and Testable Distributional Implications.” Journal of Econometrics 138: 125-180.

Andersen, T.G., T. Bollerslev, P. Frederiksen and M.Ø. Nielsen (2010). "Continuous-time Models, Realized Volatilities, and Testable Distributional Implications for Daily Stock Returns.” Journal of Applied Econometrics 25: 233-261.

Barndorff-Nielsen, O.E., and N. Shephard (2002). "Econometric Analysis ff Realized Volatility and It’s Use in Estimating Stochastic Volatility Models.” Journal of Royal Statistical Society 64: 253-280.

Barndorff-Nielsen, O.E., and N. Shephard (2004). "Power and Bipower Variation with Stochastic Volatility and Jumps.” Journal of Financial Econometrics 2: 1-37.

Barndorff-Nielsen, O.E., and N. Shephard (2006). "Econometrics of Testing for Jumps in Financial Economics Using Bipower Variation.” Journal of Financial Econometrics 4: 1-30.

Bjursell, C.J., G.H.K. Wang and R. Webb (2010). “Jumps and Trading Activity in Interest Rate Futures Markets: the Response to Macroeconomic Announcements.” Available at SSRN: http://ssrn.com/abstract=1570824.

Bredin, D., J. Elder and S. Fountas (2011). “Oil volatility and the option value of waiting: An analysis of the G-7 (2011), Journal of Futures Markets. 31:7, 679702.

Chatrath, A., H. Miao and S. Ramchander (2012). "Does the Price of Crude Oil Respond to Macroeconomic News?” Journal of Futures Markets 32: 536-559.

Dumitru, A., and G. Urga (2012). "Identifying jumps in financial assets: A Comparison between non Parametric Jump Tests.” Journal of Business and Economic Statistics 30: 242-255.

Ederington, L.H., and J.H. Lee (1993). "How Markets Process Information: News Releases and Volatility.” Journal of Finance 48: 1161-1191. 
Elder, J., H. Miao and S. Ramchander (2012). "Impact of Macroeconomic News on Metal Futures.” Journal of Banking \& Finance 36: 51-65.

Eraker, B., M. Johannes and N. Polson (2003). “The Impact of Jumps in Volatility and Returns.” Journal of Finance 58: 1269-1300.

Evans, K.P. (2011). "Intraday Jumps and U.S. Macroeconomic News Announcements.” Journal of Banking \& Finance 35: 2511-2527.

Fattouh, B., L. Kilian and L. Mahadeva (2012). "The Role of Speculation in Oil markets: What Have We Learned So Far?” Center for Economic Policy Research, Discussion Paper No. 8916.

Hamilton, J.D. (2009). "Causes and Consequences of the Oil Shock of 2007-08.” Brookings Papers on Economic Activity, Spring: 215-259.

Hamilton, J. D., and C. Wu (2012a). "Risk Premia in Crude Oil Futures Price.” University of California, San Diego, Working Paper.

Hamilton, J. D., and C. Wu (2012b). "Effects of Index-fund Investing on Commodity Futures Prices.” University of California, San Diego, Working Paper.

Jiang, G.J., I. Lo and A. Verdelhan (2011). "Information Shocks, Liquidity Shocks, Jumps, and Price Discovery: Evidence from the U.S. Treasury Market." Journal of Financial and Quantitative Analysis 46: 527-551.

Kilian, L., and B. Hicks (2012). "Did Unexpectedly Strong Economic Growth Cause the Oil Price Shock of 2003-2008?” Journal of Forecasting, forthcoming, doi: 10.1002/for.2243.

Kilian, L. and D. Murphy (2012). "The Role of Inventories and Speculative Trading in the Global Market for Crude Oil.” Journal of Applied Econometrics, forthcoming.

Kilian, L., and C. Vega (2011). "Do Energy Prices Respond to U.S.

Macroeconomic News? A Test of the Hypothesis of Predetermined Energy

Prices.” Review of Economics and Statistics 93: 660-671.

Lahaye, J., S. Laurent and C.J. Neely (2011). "Jumps, Cojumps and

Macroannouncements.” Journal of Applied Econometrics 26: 893-921.

Lee, S.S. (2012). “Jumps and Information Flow in Financial Markets.” Review of Financial Studies 25: 439-479.

Lee, S.S., and P.A. Mykland (2008). "Jumps in Financial Markets: A New Nonparametric Test and Jump Dynamics.” Review of Financial Studies 21: 2535-2563.

Masters, M.W. (2008). "Testimony before the U.S. Senate Committee on Homeland Security and Governmental Affairs.” June 24.

Maheu, J.M., and T.H. McCurdy (2004). "News Arrival, Jump Dynamics, and Volatility Components for Individual Stock Returns.” Journal of Finance 59: 755-793. 
Rangel, J.G. (2011). "Macroeconomic News, Announcements, and Stock

Market Jump Intensity Dynamics.” Journal of Banking \& Finance 35: 1263-

1276.

Simpson, M.W., and S. Ramchander (2004). "An Examination of the Impact of Macroeconomic News on the Spot and Futures Treasuries Markets.” Journal of Futures Markets 24: 453-478.

Tang, K. and W. Xiong (2011). "Index Investment and the Financialization of Commodities.” Princeton University, Working Paper. 


\section{Appendix}

This appendix describes the rejection region calculated by Lee and Mykland (2008) for the jump test statistic given by equation (2). This rejection region is based on the empirical distribution of the test statistic. In particular, the rejection region for the null hypothesis of no jump between $t_{i-1}$ and $t_{i}$ at a given significance level $\alpha$ is given by

$\frac{|\mathcal{L}(i)|-C_{n}}{S_{n}}>-\log (-\log (1-\alpha))$,

where,

$C_{n}=\frac{(2 \log (n))^{1 / 2}}{c}-\frac{\log (\pi)+\log (\log (n)}{2 c(2 \log (n))^{\frac{1}{2}}}$,

and

$S_{n}=\frac{1}{2 c(2 \log (n))^{1 / 2}}$,

where $n$ is the number of observations over the full sample. 


\section{Table 1. Economic News Announcements}

This table reports summary statistics on our sample of economic announcements. The sample is January 2005 through December 2010.

\begin{tabular}{lrrr}
\hline \multicolumn{1}{c}{ News } & Obs. & Mean & Std Dev \\
\hline 8:30 News Announcements: & & & \\
Advanced Retail Sales (ARS) & 72 & 0.0001 & 0.0060 \\
Changes in Nonfarm Payrolls (CNP) & 72 & -13.6670 & 66.6115 \\
Consumer Price Index (CPI) & 72 & 0.0000 & 0.0015 \\
Durable Goods Orders (DGO) & 72 & -0.0017 & 0.0249 \\
Gross Domestic Product (GDP) & 72 & -0.0004 & 0.0046 \\
Housing Starts (HS) & 72 & 1.4167 & 88.0807 \\
Personal Consumption (PC) & 72 & -0.0002 & 0.0036 \\
Personal Income (PI) & 72 & 0.0007 & 0.0035 \\
Producer Price Index (PPI) & 72 & 0.0005 & 0.0056 \\
Trade Balance Goods and Services (TBGS) & 72 & 0.3125 & 3.5466 \\
& & & \\
10:30 News Announcements: & & & \\
Total Change in Crude Oil Inventory (DOE) & 312 & -21.72 & 2999.60 \\
\hline
\end{tabular}




\section{Table 2. Characteristics of Jumps in the Pit and Electronic Markets}

This table reports the characteristics of jumps at different sampling frequencies (1, 5, 1015 and 30 minutes) and the $1 \%$ and 5\% significance level. P(Jump) refers to the probability of a jump. The sample is January 2005 through December 2010.

\begin{tabular}{|c|c|c|c|c|c|c|c|}
\hline \multirow[b]{2}{*}{$\begin{array}{l}\text { Significance } \\
\text { Level }\end{array}$} & \multirow{2}{*}{$\begin{array}{l}\text { Sampling } \\
\text { Frequency }\end{array}$} & \multicolumn{3}{|c|}{ Globex } & \multicolumn{3}{|c|}{ Pit } \\
\hline & & Nobs & Jumps & $\begin{array}{c}\text { P(Jump) } \\
(\%)\end{array}$ & Nobs & Jumps & $\begin{array}{c}\text { P(Jump) } \\
(\%)\end{array}$ \\
\hline \multirow{5}{*}{$0.1 \%$} & $1 \mathrm{M}$ & 1084441 & 9641 & 0.8890 & 461923 & 1301 & 0.2816 \\
\hline & $5 \mathrm{M}$ & 285096 & 1315 & 0.4612 & 94882 & 260 & 0.2740 \\
\hline & $10 \mathrm{M}$ & 149884 & 740 & 0.4937 & 48086 & 112 & 0.2329 \\
\hline & $15 \mathrm{M}$ & 101094 & 419 & 0.4145 & 31688 & 78 & 0.2461 \\
\hline & $30 \mathrm{M}$ & 51489 & 242 & 0.4700 & 16419 & 42 & 0.2558 \\
\hline \multirow{5}{*}{$1 \%$} & $1 \mathrm{M}$ & 1084441 & 13480 & 1.2430 & 461923 & 1972 & 0.4269 \\
\hline & $5 \mathrm{M}$ & 285096 & 2026 & 0.7106 & 94882 & 417 & 0.4395 \\
\hline & $10 \mathrm{M}$ & 149884 & 1179 & 0.7866 & 48086 & 211 & 0.4388 \\
\hline & $15 \mathrm{M}$ & 101094 & 675 & 0.6677 & 31688 & 145 & 0.4576 \\
\hline & $30 \mathrm{M}$ & 51489 & 392 & 0.7613 & 16419 & 83 & 0.5055 \\
\hline \multirow{5}{*}{$5 \%$} & $1 \mathrm{M}$ & 1084441 & 17473 & 1.6112 & 461923 & 2768 & 0.5992 \\
\hline & $5 \mathrm{M}$ & 285096 & 2725 & 0.9558 & 94882 & 598 & 0.6303 \\
\hline & $10 \mathrm{M}$ & 149884 & 1603 & 1.0695 & 48086 & 325 & 0.6759 \\
\hline & $15 \mathrm{M}$ & 101094 & 954 & 0.9437 & 31688 & 239 & 0.7542 \\
\hline & $30 \mathrm{M}$ & 51489 & 550 & 1.0682 & 16419 & 134 & 0.8161 \\
\hline
\end{tabular}




\section{Table 3. Descriptive Statistics on Jumps Sampled at Five-minute Frequency}

This table reports descriptive statistics on returns and jumps in oil futures returns sampled at five-minute frequencies. Prob(Jumpday) is the unconditional probability of a jump in one day. $\mathrm{E}$ (\#Jump|Jump Day) is the average number of jumps conditional on the day containing at least one jump. E(|jumpsize| | jump) is the average absolute value of the jump return. Std(|jumpsize| | jump) is the standard deviation of the absolute value of the jump. Other variables are defined similarly. The sample is January 2005 through December 2010.

\begin{tabular}{lrr}
\hline & \multicolumn{1}{c}{ Globex } & \multicolumn{1}{c}{ Pit } \\
\hline Observations & 285096 & 94882 \\
\hline Mean return & -0.0003 & -0.0002 \\
Std. deviation of return & 0.1033 & 0.2465 \\
Min return & -4.5410 & -3.4177 \\
Max return & 3.7567 & 7.0524 \\
Skewness of return & -0.3094 & 0.1269 \\
Kurtosis of return & 49.3942 & 19.5560 \\
\hline E(|abs(return)|) (\%) & 0.0594 & 0.1656 \\
Days & 1481 & 1480 \\
Jump Days & 1009 & 319 \\
Prob(Jumpday) (\%) & 0.6813 & 0.2155 \\
E(\#Jump | Jump Day) & 2.0079 & 1.3072 \\
\hline Jumps & 2026 & 417 \\
Prob(jump) (\%) & 0.7106 & 0.4395 \\
E(|jumpsize| | jump) & 0.4390 & 1.0655 \\
Std(|jumpsize| | jump) (\%) & 0.3169 & 0.6521 \\
\hline Positive Jumps & 941 & 167 \\
Prob(jump>0) (\%) & 0.3301 & 0.1760 \\
E(jumpsize|jump>0) & 0.4286 & 1.1123 \\
Std(jumpsize|jump>0) (\%) & 0.3095 & 0.7831 \\
\hline Negative Jumps & 1085 & 250 \\
Prob(jump<0) (\%) & 0.3806 & 0.2635 \\
E(jumpsize|jump<0) & -0.4480 & -1.0342 \\
Std(jumpsize|jump<0) (\%) & 0.3231 & 0.5470 \\
\% of Negative Jumps & 53.5538 & 59.9520 \\
\hline
\end{tabular}




\section{Table 4. Large Jumps and Macroeconomic Announcements}

This table reports the twenty largest jumps along with the macroeconomic announcements listed in Table 1, if any, that preceded them. For jumps at the 8:35 interval, three were preceded by two macroeconomic announcements (six, seven and 14) and two jumps were not preceded by any of the macroeconomic announcements listed in Table 1.

\begin{tabular}{|c|c|c|c|c|c|c|c|c|c|}
\hline \multicolumn{6}{|c|}{ 8:35 Jumps } & \multicolumn{4}{|c|}{ 10:35 Jumps } \\
\hline Rank & Date & Return & News & $\begin{array}{l}\text { Standardized } \\
\text { Surprise } \\
\end{array}$ & Date & Return & News & Actual & $\begin{array}{l}\text { Standardized } \\
\text { Surprise } \\
\end{array}$ \\
\hline 1 & 8/7/2009 & 1.8741 & CNP & 1.1710 & $1 / 7 / 2009$ & -2.7464 & Crude & 6682 & 1.9609 \\
\hline 2 & $12 / 5 / 2008$ & -1.5321 & CNP & -2.9725 & 6/8/2005 & 2.3920 & Crude & -3094 & -0.9481 \\
\hline 3 & $6 / 5 / 2009$ & 1.4209 & CNP & 2.6272 & $2 / 11 / 2009$ & -2.2377 & Crude & 4717 & 0.6558 \\
\hline 4 & $12 / 4 / 2009$ & 1.3216 & CNP & 1.7114 & $1 / 18 / 2007$ & -2.2271 & & & \\
\hline 5 & $11 / 7 / 2008$ & -1.1885 & CNP & -0.6005 & 5/4/2005 & -2.2246 & Crude & 2600 & 0.4501 \\
\hline $6 a$ & 4/14/2009 & -1.1641 & ARS & -2.3463 & 4/27/2005 & -1.9654 & Crude & 5500 & 1.6169 \\
\hline $6 \mathrm{~b}$ & 4/14/2009 & -1.1641 & PPI & 2.1393 & -- & --- & --- & --- & --- \\
\hline $7 a$ & $11 / 25 / 2008$ & 1.1592 & GDP & 0.0000 & 4/9/2008 & 1.8581 & Crude & -3148 & -1.8162 \\
\hline $7 b$ & $11 / 25 / 2008$ & 1.1592 & PC & -1.4056 & -- & --- & --- & --- & --- \\
\hline 8 & 9/25/2009 & -1.0526 & DGO & -1.1239 & 8/19/2009 & 1.8060 & Crude & -8397 & -3.1994 \\
\hline 9 & $10 / 2 / 2009$ & -1.0501 & CNP & -1.3211 & $6 / 27 / 2007$ & 1.5953 & Crude & 1562 & -0.0127 \\
\hline 10 & $11 / 6 / 2009$ & -1.0238 & CNP & -0.2252 & $10 / 24 / 2007$ & 1.5907 & Crude & -5288 & -2.0838 \\
\hline 11 & $8 / 19 / 2010$ & -0.9020 & --- & --- & 2/16/2005 & -1.5748 & Crude & 2100 & 0.3667 \\
\hline 12 & $5 / 13 / 2009$ & -0.8998 & ARS & -0.6704 & $3 / 16 / 2005$ & 1.5448 & Crude & 2600 & 0.2000 \\
\hline 13 & 6/4/2010 & -0.8802 & CNP & -1.5763 & 2/2/2005 & -1.4878 & Crude & -300 & -0.7668 \\
\hline $14 \mathrm{a}$ & $12 / 24 / 2008$ & -0.8646 & DGO & 0.8028 & $1 / 6 / 2010$ & -1.4315 & Crude & 1329 & 0.7764 \\
\hline $14 \mathrm{~b}$ & $12 / 24 / 2008$ & -0.8646 & PI & -0.5779 & --- & --- & --- & --- & --- \\
\hline 15 & 6/4/2009 & 0.8310 & --- & --- & $11 / 21 / 2007$ & 1.3814 & Crude & -1071 & -0.6071 \\
\hline 16 & $2 / 5 / 2010$ & 0.7941 & CNP & -0.5254 & 9/16/2009 & 1.3510 & Crude & -4729 & -0.7431 \\
\hline 17 & 9/3/2010 & 0.7878 & CNP & 0.7656 & $5 / 29 / 2008$ & 1.3457 & -- & -- & -- \\
\hline 18 & 6/11/2010 & -0.7759 & ARS & -2.3463 & 2/9/2005 & 1.3216 & Crude & -1000 & -0.5667 \\
\hline 19 & 10/8/2010 & 0.7394 & CNP & -1.3511 & $11 / 22 / 2006$ & -1.2867 & Crude & 5161 & 1.4872 \\
\hline 20 & $2 / 19 / 2009$ & -0.7257 & PPI & -0.8914 & $3 / 12 / 2008$ & -1.2478 & Crude & 6177 & 1.5009 \\
\hline
\end{tabular}




\section{Table 5. Jump Returns Matched with Macroeconomic News Releases}

This table reports the number and proportion of each type of news announcement that immediately precedes a jump in oil returns.

\begin{tabular}{llcc}
\hline & News & Matched & Percentage \\
\hline & ARS & 5 & 6.94 \\
& CNP & 23 & 31.94 \\
& CPI & 3 & 4.17 \\
& DGO & 6 & 8.33 \\
& GDP & 9 & 12.50 \\
8:35 Jumps & HS & 6 & 8.33 \\
and 8:30 news & PC & 9 & 12.50 \\
& PI & 1 & 1.39 \\
& PPI & 6 & 8.33 \\
& TBGS & 1 & 1.39 \\
& Total jumps & 78 & \\
& Jump match news & 56 & 71.79 \\
\hline 10:35 Jumps & DOE Crude Inventory & 64 & 20.51 \\
and 10:30 News & Total jumps & 75 & \\
(DOE) & Jump match news & 64 & 85.33 \\
\hline
\end{tabular}




\section{Table 6. Marginal Impact of Macroeconomic News on Jumps}

This table reports results from the panel regression: $j p_{t_{j}}=c+\sum_{i=1}^{n} c_{i}^{+} S A_{i, t_{j}}^{+}+\sum_{i=1}^{n} c_{i}^{-} S A_{i, t_{j}}^{-}+\varepsilon_{t_{j}}$. That is, jumps in oil returns that are preceded by at least one news announcement are regressed on these standardized news surprises. One regression is reported for 8:30 am news announcements, and one for 10:30am news announcements.

Jumps and News Announcements

\begin{tabular}{|c|c|c|c|c|c|c|c|}
\hline \multirow{21}{*}{$\begin{array}{l}\text { 8:30am } \\
\text { News }\end{array}$} & Variable & Estimate & t-stat & p-value & Estimate & t-stat & p-value \\
\hline & $\mathrm{ARS}^{+}$ & -0.5059 & -0.66 & 0.5127 & & & \\
\hline & $\mathrm{CNP}^{+}$ & 0.6429 & $3.26^{* *}$ & 0.0024 & & & \\
\hline & $\mathrm{CPI}^{+}$ & 0.0000 & -- & --- & & & \\
\hline & $\mathrm{DGO}^{+}$ & 0.0595 & 0.13 & 0.9008 & & & \\
\hline & $\mathrm{GDP}^{+}$ & 0.1945 & 0.35 & 0.7293 & & & \\
\hline & $\mathrm{HS}^{+}$ & 0.1691 & 0.70 & 0.4857 & & & \\
\hline & $\mathrm{PC}^{+}$ & 0.2778 & 0.48 & 0.6363 & & & \\
\hline & $\mathrm{PI}^{+}$ & 0.0000 & --- & --- & & & \\
\hline & $\mathrm{PPI}^{+}$ & -0.3164 & -0.73 & 0.4725 & & & \\
\hline & TBGS $^{+}$ & 0.9216 & 1.09 & 0.2810 & & & \\
\hline & $\mathrm{ARS}^{-}$ & 0.2975 & 1.39 & 0.1731 & & & \\
\hline & $\mathrm{CNP}^{-}$ & 0.3333 & $2.03^{* *}$ & 0.0490 & & & \\
\hline & $\mathrm{CPI}^{-}$ & -0.6556 & -0.68 & 0.4986 & & & \\
\hline & $\mathrm{DGO}^{-}$ & 0.8487 & 1.49 & 0.1453 & & & \\
\hline & $\mathrm{GDP}^{-}$ & 0.1288 & 0.24 & 0.8124 & & & \\
\hline & $\mathrm{HS}^{-}$ & -1.5643 & -1.15 & 0.2568 & & & \\
\hline & $\mathrm{PC}^{-}$ & -0.5000 & -1.50 & 0.1415 & & & \\
\hline & $\mathrm{PI}^{-}$ & 1.4079 & 1.16 & 0.2544 & & & \\
\hline & $\mathrm{PPI}^{-}$ & 0.2159 & 0.72 & 0.4783 & & & \\
\hline & TBGS $^{-}$ & 0.0000 & --- & --- & & & \\
\hline \multirow{2}{*}{$\begin{array}{l}\text { 10:30am } \\
\text { News }\end{array}$} & Crude Inv $^{+}$ & --- & --- & --- & -0.7808 & $-3.75^{* * *}$ & 0.0004 \\
\hline & Crude Inv ${ }^{-}$ & --- & --- & --- & -0.5275 & $-2.97^{* * *}$ & 0.0043 \\
\hline \multirow{5}{*}{ Model } & Time & \multicolumn{3}{|c|}{ 8:30-8:35 am } & \multicolumn{3}{|c|}{ 10:30-10:35 am } \\
\hline & Obs & \multicolumn{3}{|c|}{56} & \multicolumn{3}{|c|}{64} \\
\hline & $\operatorname{Adj}-R^{2}(\%)$ & \multicolumn{3}{|c|}{31.63} & \multicolumn{3}{|c|}{38.90} \\
\hline & F-Value & \multicolumn{3}{|c|}{$2.5000^{* * *}$} & \multicolumn{3}{|c|}{$21.05^{* * *}$} \\
\hline & P-value & \multicolumn{3}{|c|}{0.0095} & \multicolumn{3}{|c|}{0.0000} \\
\hline
\end{tabular}




\section{Table 7: News Related Jumps relative to Non News Related Jumps}

This table reports summary statistics on oil return jumps associated with our sample of econmic news announcements and oil return jumps not associated economic news announcements. JV refers to the jump component (or jump variance); RV is the daily realized volatility.

\begin{tabular}{|c|c|c|c|c|c|c|c|c|}
\hline \multirow[t]{2}{*}{ Variable } & \multicolumn{4}{|c|}{ Globex (8:35 am) } & \multicolumn{4}{|c|}{ Pit (10:05) } \\
\hline & \multicolumn{2}{|c|}{ News } & \multicolumn{2}{|c|}{ No News } & \multicolumn{2}{|c|}{ News } & \multicolumn{2}{|c|}{ No News } \\
\hline \multirow[t]{2}{*}{ OBS } & \multicolumn{2}{|c|}{56} & \multicolumn{2}{|c|}{1970} & \multicolumn{2}{|c|}{64} & \multicolumn{2}{|c|}{353} \\
\hline & Mean & StdEv & Mean & StdEv & Mean & StdEv & Mean & StdEv \\
\hline |Returns| & 0.6519 & 0.3587 & 0.4329 & 0.3137 & 1.1114 & 0.4764 & 1.0571 & 0.6794 \\
\hline JV & 0.2361 & 0.4322 & 0.1606 & 0.5909 & 0.8094 & 0.9356 & 0.7373 & 1.7937 \\
\hline JV/RV (\%) & 9.2713 & 10.8984 & 8.5739 & 11.2349 & 17.8976 & 16.0809 & 11.1683 & 11.9565 \\
\hline
\end{tabular}


Table 8: Volatility Persistence after Jumps

This table reports the results from the regression $r_{t_{j+i}}^{2}=\beta_{n j} N J D_{t_{j}}+$ $\beta_{n n j} N N J D_{t_{j}}+\varepsilon_{t_{j+i}}$, for $i=1$ to 5 for dummy variables on news related jumps (NJ) and non-news related jumps (NNJ).

Panel A: Volatility persistence using intraday jump dummies on Globex returns

\begin{tabular}{rrrrrrrr}
\hline & \multicolumn{3}{c}{ NJ } & \multicolumn{3}{c}{ NNJ } & \\
\cline { 1 - 6 } Lead & Estimate & T-stat & p-value & Estimate & T-stat & $\begin{array}{c}\text { p- } \\
\text { value }\end{array}$ & \\
\hline 1 & 0.5513 & 5.3771 & 0.0000 & 0.2739 & 14.4661 & 0.0000 & 0.1221 \\
2 & 0.0732 & 1.2081 & 0.2272 & 0.0693 & 6.0444 & 0.0000 & 0.0217 \\
3 & 0.1203 & 3.7893 & 0.0002 & 0.0405 & 6.6748 & 0.0000 & 0.0346 \\
4 & 0.0930 & 3.7900 & 0.0002 & 0.0418 & 8.8230 & 0.0000 & 0.0546 \\
5 & 0.0573 & 3.0493 & 0.0023 & 0.0358 & 9.7581 & 0.0000 & 0.0630 \\
6 & 0.0852 & 4.6765 & 0.0000 & 0.0305 & 8.4474 & 0.0000 & 0.0586 \\
\hline
\end{tabular}

Panel B: Volatility persistence using intraday jump dummies on pit returns

\begin{tabular}{cccccccc}
\hline & \multicolumn{3}{c}{$\mathrm{NJ}$} & \multicolumn{3}{c}{ NNJ } & \\
\cline { 1 - 6 } Lead & Estimate & T-stat & $\begin{array}{l}\text { p- } \\
\text { value }\end{array}$ & Estimate & T-stat & $\begin{array}{l}\text { p- } \\
\text { value }\end{array}$ & Adj-R \\
\hline 1 & 1.4586 & 6.8320 & 0.0000 & 1.2679 & 11.1111 & 0.0000 & 0.3686 \\
2 & 0.1394 & 3.2152 & 0.0015 & 0.1931 & 8.1627 & 0.0000 & 0.2118 \\
3 & 0.1686 & 2.9794 & 0.0031 & 0.1288 & 4.1616 & 0.0000 & 0.0801 \\
4 & 0.0981 & 3.0132 & 0.0028 & 0.1322 & 7.3746 & 0.0000 & 0.1827 \\
5 & 0.0889 & 3.2345 & 0.0014 & 0.1046 & 6.9548 & 0.0000 & 0.1698 \\
6 & 0.0780 & 2.1397 & 0.0333 & 0.0927 & 4.6568 & 0.0000 & 0.0800 \\
\hline
\end{tabular}


Figure 1: Distribution of jumps across time intervals

This figure reports the number of jumps at each five-minute interval during the trading day.

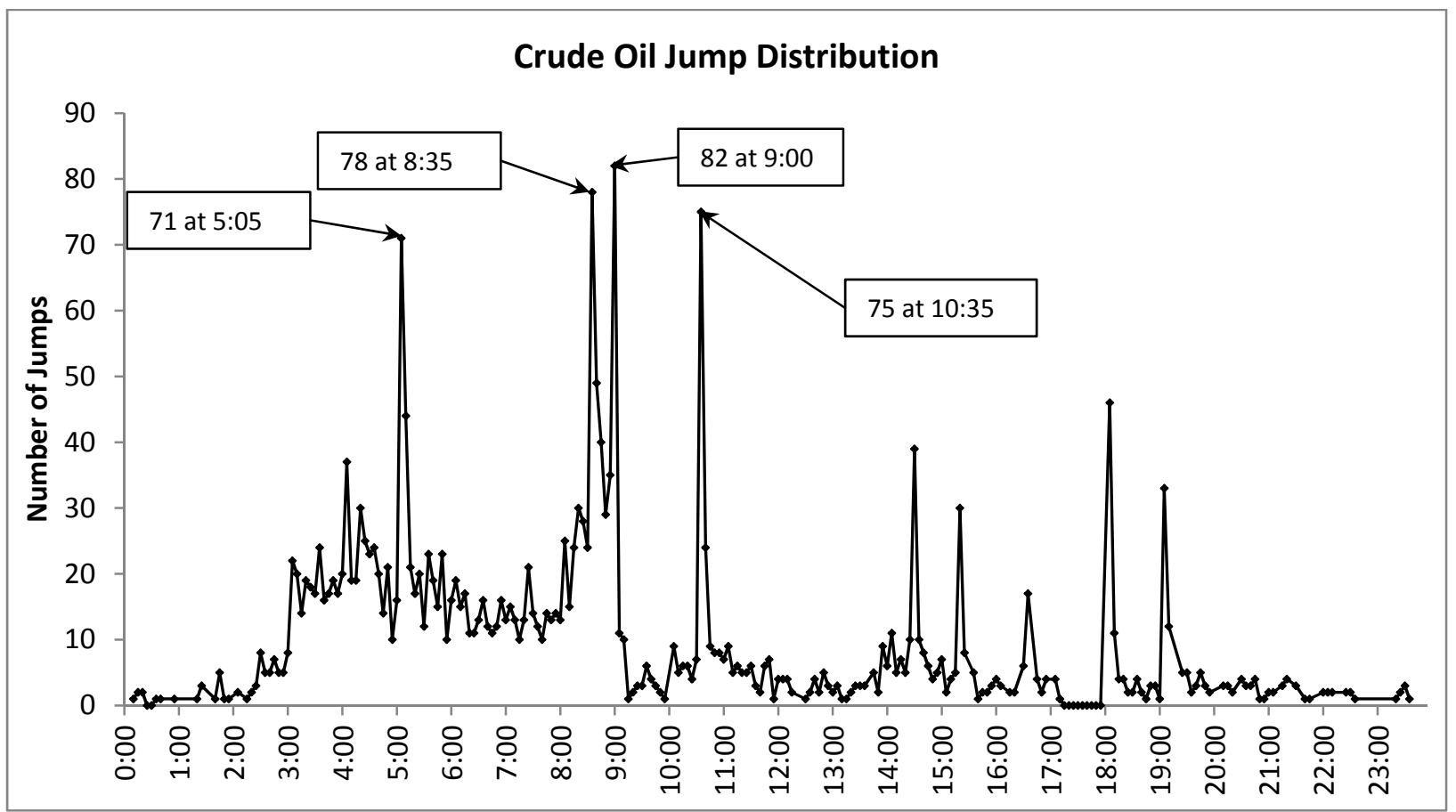

